\title{
Mulheres negras na formação de docentes: identidades e estratégias de resistência em uma escola pública de Curitiba-PR
}

\author{
Aline Adriana de Oliveira \\ Carolina dos Anjos de Borba ${ }^{2}$ \\ Recebido em março de 2021 \\ Aceito em junho de 2021
}

\section{RESUMO}

Neste artigo discutimos os resultados de pesquisa realizada entre 2018 e 2019 com alunas de uma turma do curso de formação de docentes em uma escola pública de Curitiba - PR. O objetivo era buscar uma aproximação entre a formação escolar e a construção de identidades negras, ou seja, compreender como "raça" enquanto temática foi mobilizada no cotidiano escolar, tal qual a maneira como emerge em narrativas identitárias formuladas pelas alunas. O recorte proposto procura compreender como estudantes que se veem como negras articulam suas identidades no espaço da escola, compreendendo tais identidades numa perspectiva que as entende como sendo negociadas e marcadas pelas diversas posições que os sujeitos ocupam. Através de etnografia, entrevistas semiestruturadas e um questionário de autoidentificação de raça-cor utilizado com a turma, os resultados sugerem a manutenção de formas diversas de racismos que se transmutam num sentimento difuso de "incapacidade" e falta de amparo em relação às estudantes que se autodeclaram negras, bem como a carência de abertura para o tema da história e cultura afro-brasileira nos currículos. Por fim, percebe-se como dos conflitos surgem estratégias de resistências, sobretudo para aquelas mulheres que se veem como negras e militantes e passam a reivindicar suas demandas na instituição escolar.

Palavras-chave: Mulheres Negras; Identidades; Formação de Docentes; Ambiente Escolar, Relações Étnico-Raciais.

\section{Black women on teacher training: the identities and resistance strategies at a public school in Curitiba-PR}

\begin{abstract}
In this text we discuss the results of research developed between 2018 and 2019, with female students from a class of the teaching training course at a public school in Curitiba - PR. The study aims to approach the school education and the black identities' formulation, meaning comprehending how "race" as a theme was discussed within the everyday life at school, as well as the way how it brings up

\footnotetext{
${ }^{1}$ Mestranda no Programa de Pós-Graduação em Educação da Universidade Federal do Paraná (UFPR), na linha de Diversidade, Diferença e Desigualdade social em Educação e licenciada em Ciências Sociais na Universidade Federal do Paraná (UFPR). Contato: aline.adriana.oliveira@gmail.com.

2 Possui graduação em Direito pela Universidade Federal de Pelotas (2006), mestrado (2008) e doutorado (2013) em Desenvolvimento Rural pela Universidade Federal do Rio Grande do Sul. Atualmente é professora adjunta na Universidade Federal do Paraná, atuando no Setor de Educação, no Pós-Graduação em Educação e no Pós-Graduação em Meio Ambiente e Desenvolvimento. Contato: carolzinhadosanjos@gmail.com.
} 
the identity narratives expressed by the students. The emphasis proposed aims to understand how the students who identify themselves as black women express their identities on the scholar environment, those identities understood as negotiated and brought by the various positions occupied by the subjects. Through ethnographic research, semi-structured interviews and a race/ skin color self-identification survey made on the class, the results shows some different racism forms that can be seen as a diffuse feeling of "incapacity" and loss of support regarding the female students self identified as black women, also there is the low entry for the African-Brazilian history and culture on the curricula. The conflicts open space to resistance strategies specially from those students who claim themselves as black women and political agents and fight for their demands within the school.

Palavras-chave: Black Women; Identities; Teaching Training; School Environment, Racial Relationships.

artigo lança mão de achados colhidos durante pesquisa realizada entre 2018 e 2019 em uma escola de formação de docentes na cidade de Curitiba, cujo tema é a construção das identidades de mulheres negras no âmbito da educação escolar. Para tanto, foi utilizado o método etnográfico e entrevista semiestruturada com alunas que se autodeclararam negras, estudantes da turma do $3^{\mathbf{o}}$ ano noturno da formação de docentes.

Na medida em que se intensifica o debate sobre raça/cor no Brasil, tanto no ambiente acadêmico quanto na esfera política (CARVALHO; SEGATO, 2004; MAGGUY; FRY, 2002), impulsionado pela implantação das cotas para acesso ao ensino superior, tornam-se latentes duas questões: quem é negra em um país miscigenado como o Brasil? Como se definem essas identidades raciais? Além da emergência da temática, estudos como os de Rosemberg (1987) e Hasenbalg \& Silva (1990) mostram como, no Brasil, a população negra teve acesso diferenciado à educação, compondo o grupo racial que alcançou, ao longo do século XX, menores níveis educacionais.

O que se pretende discutir nesse trabalho é a maneira como as identidades são mobilizadas pelos sujeitos enquanto processos sociais. Por essa razão, assumimos o suposto de que elas são contrastivas e plurais, não sendo fixas, mas construídas em determinados contextos (HALL, 2006; WOODWARD, 2014). Nesse sentido, e será importante para a nossa argumentação, interessa-nos a intersecção entre diferentes marcadores sociais na construção dessas identidades, notadamente raça e gênero. Ao privilegiar a maneira como essas estudantes, em cursos de formação de docentes, articulam suas identidades, é possível observar, no quadro social mais amplo, como a 
escola, enquanto espaço de socialização e formação, mostra-se, ou não, como sendo um ambiente (re)produtor de desigualdades.

O estudo buscou analisar também quais são os marcadores simbólicos mobilizados pelas jovens negras na veiculação de suas imagens no afã de compreender de que modo aparece, no ambiente escolar, a questão da raça/cor e entender a forma como essas mulheres projetam seus futuros. Esses objetivos auxiliaram a pensar como elas percebem a influência do processo de escolarização sobre sua construção identitária, também o modo como narram o seu pertencimento identitário.

Já há um acúmulo de estudos que indicam como os currículos e práticas escolares atuam na reprodução de racismos ao ver as diferenças como nocivas, tornadas desigualdades (GOMES, 2007; LOURO, 1997; DUSCHATZKY; SKLIAR, 2000). Para Walsh (2009), isto seria fruto da manutenção de uma concepção epistêmica eurocentrada, que instaura uma relação hierárquica entre saberes e a racialização das esferas de poder, reflexo da colonialidade. Em contrapartida, o espaço escolar não deixa de ser palco de disputas de sentidos, funções e direitos. A educação reproduz preconceitos, mas oportuniza resistências. Essa ambivalência também foi flagrada na pesquisa, como será discutido a seguir.

No decorrer do texto, ao nos referirmos às estudantes com quem houve contato em campo, buscando preservar o anonimato, atribuímos nomes fictícios referentes a personalidades da cultura afro-brasileira. A primeira é Dandara de Palmares (?-1654), logo após João Francisco dos Santos, conhecido como Madame Satã (1900-1976), Tereza de Benguela (S.I. - viveu no século XVIII), Carolina Maria de Jesus (1914-1976), Esperança Garcia (1751-) e Maria Firmina dos Reis (1822-1917).

\section{Identidade, negritude e mulheres negras na educação: debates teóricos}

Ao pesquisar processos de formação identitária, a primeira questão que se coloca é compreender o que se entende por identidade e diferença. Para Hall (2006), as identidades são móveis, contingentes, múltiplas, suscetíveis ao modo como somos representados e nos representamos, nos sistemas culturais em que estamos inseridos. As identidades, que são construídas no âmbito da diversidade, pressupõem alteridades. 
Segundo Woodward (2014), a depender do momento histórico, algumas diferenças são mais significativas que outras, estabelecendo padrões de desigualdade. Identidade não é, desse modo, o oposto de diferença, ela depende da diferença no processo de circunscrição do nós e do outro.

A reivindicação de uma identidade negra implica a formação de um olhar dos sujeitos que pertencem a um grupo étnico-racial sobre si e sobre o outro (GOMES, 2003). Como as identidades são construídas em determinados contextos sociais e (re)formuladas em diversos momentos históricos, alguns autores retomam a história das relações raciais no Brasil e os papéis sociais ocupados pelos negros ao longo da constituição da nação. É assim que Munanga (2003) sugere que a construção da negritude enquanto forma de identificação remonta ao colonialismo e à mestiçagem, acionada enquanto meio para branqueamento da população brasileira no início do século XX, acompanhada do rechaçamento à cultura afro-brasileira, sobrepondo a esta uma identidade nacional. O que teria formado um racismo que "trata a si mesmo como antirracismo, negando como antinacional a presença integral do afro-brasileiro [...]” (GUIMARÃES, 1995, p. 42). Munanga (2003) argumenta que tal processo teria gerado uma cultura de discriminação racial velada, não dita. Na mesma direção de Segato (2005), quando afirma que raça é signo. Raça seria uma forma de qualificação ancorada nos sistemas de representações sociais e esses sistemas são, no Brasil, discriminatórios contra as negras e os negros. Nesse sentido, Nogueira (2007) apontou que o racismo brasileiro se constitui a partir de critérios fenotípicos e se expressa através do corpo que, ao ser mobilizado como componente político pelo movimento, na ideia de “negritude”, retomando Munanga (2003), é ressignificado. Valorizam-se, com isso, os traços fenotípicos socialmente rejeitados, ou seja, a "aparência racial"(NOGUEIRA, 2007) importa e passa a ser associada à ancestralidade africana. Portanto, o corpo e o cabelo, tal como ressalta Gomes (2008), tornam-se elementos decisivos para uma identidade negra.

A condição de mulher opera como outro elemento balizador de condutas num contexto social marcado por clivagens entre os gêneros, mas também entre as mulheres, tal como levantado pelas mulheres negras (LOURO, 1997). A confluência de formas de opressão distintas movimentou a necessidade de se pensar abordagens 
analíticas que incluam raça, classe e gênero como estruturas de opressão imbricadas (COLLINS, 2015). É nesse sentido que Crenshaw (2004; 2006) formula o conceito de interseccionalidade, que descreve tanto a articulação e a interação entre o sexismo e o racismo como descreve a localização de mulheres negras em ambos os sistemas de subordinação, nas margens do feminismo e do antirracismo.

No Brasil, a posição social das mulheres negras levantou debates acadêmicos e políticos desde a década de 1980. A articulação do racismo com o sexismo produziria, segundo Gonzales (1984), efeitos violentos sobre as mulheres negras, que seriam representadas como "mulatas" de exportação, como empregadas domésticas, ou como mães pretas, tal como discute Segato (2006). Por essa razão, Carneiro (2003) argumenta a favor da necessidade de "enegrecer" o feminismo para captar as formas de opressão que atingem de maneira particular as mulheres negras. Não é à toa que Guimarães (1995) chama a atenção para o uso, no Brasil, do gênero como metáfora da raça. É nesse cenário, em que tanto gênero quanto raça estabelecem critérios de desigualdade social implícita, que se está tentando pensar a formação das identidades de mulheres negras.

Diante desse contexto, onde fica a educação em um contexto social marcado por essas manifestações de desigualdades? De que forma atua na sua perpetuação, ou superação? Guimarães (1995) ressalta que a lógica nacional racializada, que operou desigualdades entre negros e brancos, passou por dois elementos principais: classe/renda e educação. O acesso à educação acabou se transformando em medida de cidadania e branqueamento, uma vez que a população negra era majoritariamente analfabeta. Gonçalves e Silva (2000) apontam as leis educacionais do início do século $\mathrm{XX}$ que não abrangiam as crianças negras, sendo setores do movimento negro, em especial em São Paulo, articuladores de escolas para alfabetização dessa parcela da população ignorada pelo Estado até meados do século passado.

Outros pesquisadores do campo da educação, como Gomes (2007), Arroyo (2015) e Walsh (2009), apontam a origem do pensamento educacional ocidental inscrito na lógica da dominação colonialista e do eurocentramento do saber, que desvalorizou conhecimentos e saberes daqueles considerados "diversos". Para Walsh (2009), a partir da colonialidade, as diferenças seriam marcadas por oposições binárias, 
como homem/mulher, branco/negro, saber científico/saber tradicional, sendo sempre o primeiro termo da oposição tomado como norma em detrimento do segundo. Tal estrutura se manteria ao passo em que estabeleceu a racialização das posições de poder e saber (QUIJANO, 2005).

No suposto de que educação escolar, além de promover o conhecimento científico, atua como importante esfera de socialização, inclusive refletindo desigualdades e preconceitos, temos que ela atua no processo de construção identitária dos estudantes (GOMES, 2007), o que não elimina a agência dos sujeitos e a influência dos demais espaços de socialização. A relação professor-aluno, as vozes e os silenciamentos constroem uma escola que é forte elemento na formação das identidades. Nesse entremeio, Cavalleiro (2006) aponta que o material pedagógico, um universo semântico pejorativo em relação aos símbolos da negritude, a ausência da diversidade racial na composição do corpo docente e a minimização das consequências do racismo, elementos encontrados em suas pesquisas sobre educação e relações raciais, reprisariam a racialização enquanto desigualdade através da educação. Uma escola cujo referencial é todo em torno da branquitude geraria, segundo Cavalleiro (2006), uma inadequação social das alunas e alunos negros. Esse processo ilustra o que a Gomes (1996) diz ser a rejeição da possibilidade de manifestação de uma identidade negra, ou, nos termos de Munanga (2012), a negação da negritude. Gomes (1996) afirma que, por vezes, a discriminação não se manifesta sob a forma de agressão explícita, porém se faz presente como um discurso, que perpassa as práticas. Por isso o recurso ao silenciamento parece ser acionado nesse âmbito, tal como o enunciado da igualdade (GONÇALVES, 1985). Compreender a construção da trajetória das alunas negras passa por considerar a influência de situações de racismo e discriminação no próprio ambiente escolar.

Em pesquisa com professoras pardas e pretas, Castelar et al. (2015) encontrou docentes que indicavam situações de racismo que vivenciaram, enquanto várias delas de identificam como morenas. O que sugere como a vivência e a formação das identidades na escola, colocando em relevo o critério racial, é marcada por formas de percepção distintas e, portanto, de engajamentos identitários diversos. Essa complexidade de percepções sobre si e sobre o outro, a formulação de uma 
autoimagem pelas estudantes negras, que ocorre de formas distintas para cada uma dessas mulheres, e as resistências por elas articuladas nesse meio é o que veremos a seguir.

\section{A aproximação com o campo}

Definidos tema e problemática, buscamos a melhor estratégia metodologia para compreender o processo de formação e afirmação das identidades. Optamos por realizar trabalho de campo em escola normalista da rede pública que oferecesse curso de formação de docentes, integrado ao ensino médio, em Curitiba. Isso se deve a dois principais motivos. Primeiro, pelo perfil socioeconômico: em sua composição, escolas públicas abrigam estudantes oriundos de famílias com menor renda e, como mostra Rosemberg (1987), existe forte relação entre ser pobre e ser negra(o) no Brasil. Tal tendência é corroborada pelos dados do último Censo do IBGE, quando mostra que $50 \%$ da população negra (pretos e pardos) tem rendimento nominal mensal entre $1 / 4$ de salário-mínimo e 2 salários mínimos, menor que qualquer outro grupo de raça/cor no país. Segundo, que um curso de formação de docentes seria interessante para captar como o tema da diversidade e do racismo aparece no conteúdo pedagógico.

A pesquisa etnográfica foi escolhida com o intuito de compreender como os discursos sobre diversidade de raça/cor e negritude se manifestam no cotidiano escolar. A observação foi realizada por meio de visitas à escola e as aulas da turma de $3^{\mathbf{0}}$ ano noturno da formação de docentes. Como se tratou de compreender as formações de identidades raciais, a autoidentificação importava mais do que a classificação compulsória feita pelos pesquisadores, o que levou à escolha pela aplicação de um pequeno questionário indagando a identificação étnico-racial, inspirado nas perguntas do Censo do Instituto IBGE, para as estudantes.

Em 2019, tendo já finalizado a primeira etapa, houve retorno ao campo para acompanhar algumas aulas e, principalmente, a sala dos professores com o consentimento de um dos docentes. Nesse mesmo ano, foram aprofundados alguns tópicos através de entrevista semiestruturada com duas interlocutoras. 


\section{Identidades de raça/cor: conflitos e resistências no espaço escolar}

A pesquisa de campo foi realizada em uma das escolas normalistas mais antigas do Paraná. Quando houve contato com um dos pedagogos e com a direção, foi perceptível o interesse diante do tema proposto; sugerindo que a pesquisa fosse feita com a turma do período noturno que, nas palavras do pedagogo, tinha várias alunas negras que seriam "meninas engajadas", "mais militantes", mas que, "às vezes, exageram".

Discursos e práticas sobre raça na escola foram se delineando durante o campo. Um exemplo foi no Dia da Consciência Negra, em 2018, data em que não houve atividade sobre esse dia no período noturno. Nessa ocasião, ao perceberem que nenhuma aula abordou o tema, dois alunos, Dandara e João, discutiam sobre a importância da data quando o professor que estava na classe interrompeu a conversa para dizer que "não devia haver separação entre brancos e negros". Fomos levadas a crer que história e cultura afro-brasileiras são temas pouco trabalhados no ambiente escolar e que a narrativa da escola, ao mostrar-se aberta à pesquisa e ao tema proposto, era confrontada com as práticas cotidianas em face da manifestação dos alunos mais engajados na militância negra.

Outro aspecto que me chamou a atenção foi a composição da turma na qual se acompanhou as atividades. Nela, havia apenas um menino (negro) e o restante composto por alunas (cerca de 20), dessas, metade havia se identificado no questionário como pretas e pardas. Percebemos que as indicações do pedagogo e da direção sobre quais eles viam como "militantes políticas" coincidia com um estereótipo muito associado à imagem das meninas. Era o caso de Tereza, que usava cabelo Black Power, brincos que representam pentes-garfo e camisetas de sindicatos, partidos ou coletivos. Carolina, prima de Tereza, seguia o mesmo estilo, apesar de não ser filiada a partido ou movimento social. Carolina é negra de pele retinta, enquanto Tereza tem pele mais clara. Tereza é a aluna que considero a mais engajada politicamente e com a qual fiz contato. Por ter a pele mais clara, ela afirma que era questionada pelos demais, que não a viam como ela mesma se declarava, uma mulher preta, deslegitimando sua fala quando essa identidade de raça estava em pauta. 
Com a observação dos grupos de afinidades, os discursos e práticas das estudantes ao longo de dois meses, notou-se que o tema "raça” sempre gerava polêmicas e disputas. Parecia não haver consenso entre as estudantes acerca de quem era negra, quem era branca e as nuances de legitimidade sobre quem podia falar. Numa aula de filosofia, por exemplo, discutia-se o uso do "politicamente correto" no tratamento à população negra. Maria Firmina rebateu a afirmação de uma colega branca sobre a dificuldade para se definir a denominação correta, dizendo que, como preta, achava correto chamar assim. A colega questionou sua afirmação dizendo que ela era branca. Note-se que Maria Firmina tem a pele mais clara e cabelo cacheado.

Ainda nas disputas discursivas, as representações associadas à noção de "boa aluna" e "má aluna" também permeavam o cotidiano e os papéis das diferentes estudantes na turma. João, cujo fenótipo é negro de pele retinta, alto e forte, aparecia nas falas dos docentes como "mau aluno", por vezes "perigoso". "Ele consegue acabar com uma aula se quiser", ou ainda, "ele assusta, mas não faz nada”, diziam os docentes na sala dos professores. Nas conversas com alunas, as meninas negras costumavam reclamar de perseguições e punições por parte dos professores, enquanto as meninas brancas tinham simpatia por e para eles.

Em campo, a situação apresentava-se assim. Era uma aula dedicada à finalização de um trabalho de português que tinha três critérios: a) escolha de poemas a partir da leitura de determinados autores; b) trabalho escrito justificando a escolha dos poemas; c) preparação de material para exposição dos poemas nos corredores da escola. Dandara me mostrou três livros que consultou, explicando a escolha de cada um. Seu material para exposição, porém, era feito de itens reciclados. Em determinado momento, a professora começou a visitar os grupos de trabalho com uma pedagoga, convidando-me para circular com elas. Diante de cada um dos grupos fez comentários. Elogiou o trabalho das meninas brancas e criticou o de Dandara dizendo que, por mais que se esforçasse, ela acabava fazendo as atividades errado. A aluna pareceu frustrada. Nesse mesmo dia, ainda, o grupo de João, Carolina e Esperança decidiu fazer o material para exposição com imagens de orixás, tema dos poemas escolhidos. A professora criticou o visual do material e disse que não estava tão bonito quanto os dos demais grupos. Comparação, condescendência e descontentamento por parte dos docentes 
quando apareciam referenciais da negritude se fizeram presentes no cotidiano escolar, segundo o que pude notar a partir de várias situações em campo.

Como sugere Carvalho (2004), o docente cria uma expectativa com relação à turma e ela se assenta em um apanhado de elementos simbólicos que advém da sua formação, trajetória de vida e socializações outras que fornecem critérios de julgamento. É com essa métrica que ele tentará, no ano letivo, eleger os que se encaixam nos perfis de bom ou mau aluno, tendendo a tratá-los de maneira diferenciada ao longo do ano. Tal expectativa autorrealizadora também é perpassada pelo critério racial. Os discursos dos docentes na sala dos professores, sempre criticando a postura das alunas negras daquela turma, que eles consideravam “exageradas”, parecia reforçar essa expectativa, fomentando práticas de silenciamento diante das queixas de racismos e sexismos pelas estudantes.

É nesse contexto que as estudantes encontram diferentes modos de afirmação identitária. Os resultados dos questionários aplicados sugerem tal complexidade. Havia alunas que se identificavam como pardas, a maioria se dizendo morena na pergunta aberta. Ser "negra” era uma identidade com significados distintos para elas. Não é generalizada a ideia de identidade negra enquanto ser "mulher preta", como declaravam aquelas que se afirmavam militantes. Essas identidades construídas na escola são múltiplas e passam também pela rejeição desse pertencimento identitário que demanda, provoca e se converte em ação política. Dialogando e ouvindo essas jovens, percebeu-se como os modos de identificação estão muito associados ao colorismo, remetendo à cor da pele, seja para designação de parda, preta e branca. As alunas que reivindicavam alguma militância eram as que problematizavam a categoria "pardo" e se mostravam as mais engajadas em confrontar o que consideravam racismo no ambiente escolar.

Durante a entrevista, Tereza e Dandara indicaram uma formação identitária permeada por vivências de racismo e desamparo desde a infância. A isso relacionam o papel, além da escola, da família. O tema "família” era mobilizado para falar do desamparo no sentido subjetivo, e das diferentes formas de opressão vivenciadas ainda na infância. Além da carência de suporte financeiro, que as impeliu logo cedo a conciliar trabalho e estudo, são trajetórias carregadas pela experiência do preconceito 
racial. A esse desamparo por parte da família as interlocutoras verbalizam a formação de uma autoconcepção de incapacidade, gestado neste meio, mas sentido, segundo elas, em diversas situações, em especial no processo de escolarização, ainda no presente.

Eu sei que é [racismo] só no olhar. [...] [A] primeira coisa na qual eles rotulam a gente é que a gente é incapaz de qualquer tipo de coisa, porque a gente é diferente. [...] Quando sai uma coisa bonita da nossa boca, eles ficam perdidos... (Dandara, 18 anos).

Eles ficam impressionados, como se a gente não tivesse capacidade de ser assim [inteligente]... (Tereza, 22 anos).

Tereza conta que essa perplexidade frente à sua demonstração de intelectualidade é reflexo de uma visão estereotipada da mulher negra, que seria vista como "preta raivosa, que quer brigar com todo mundo, a mulata exportação e a escrava”. Em outro momento da entrevista, Tereza foi questionada se ela ainda pretende entrar na faculdade, conforme havia mencionado em momento anterior. Ela diz que não sabe mais o que quer fazer, porque de tantas vezes que foi questionada em sua capacidade para tal, acabou desmotivada.

\footnotetext{
É uma coisa que a gente é condicionada a pensar, que a gente não é capaz, que uma mulher preta serve pra limpar a casa e só pra isso, que ela não pode estar lá em cima [...]. Eu falei do colégio, que eu não me vejo sendo pedagoga de lá daqui uns anos, porque aquilo lá não se encaixa, porque eu não me encaixo. $\mathrm{O}$ problema [...] que não é uma coisa de que eu acho que não sou capaz, eu fui ensinada de que eu não sou capaz disso... (Tereza, 22 anos).
}

Essa autopercepção verbalizada pelas estudantes como “incapacidade” pode ser relacionada ao que Batista et al (2020) chamam de autopercepção cognitiva. Para os pesquisadores, essa visão sobre si deriva de processos psicológicos vivenciados pelos alunos na escola e dizem respeito à visão destas sobre seu desempenho escolar e sobre a expectativa de desempenho. No caso das crianças e adolescentes com quem aplicaram questionários, em escolas da rede pública, entre o Fundamental II e o Ensino Médio, a autopercepção cognitiva era pior em estudantes mais velhos e dentre os que se classificaram como pretos e pardos. Os autores apontam a possível influência dos estereótipos de raça/cor tomados no ambiente escolar como fator que contribui para 
tal autopercepção cognitiva de pretos e pardos significativamente menor do que de qualquer outro grupo racial.

Por vezes, é o silenciamento que emerge como prática de opressão.

[...] Teve uma vez que eu citei isso, eu falei: "vocês nunca me deixam falar!". Falei, "a mulher preta sempre é silenciada". E eu falei sério e eu olhei pra todo mundo da sala, as pessoas começaram a rir... Eu falei: "estão fazendo de novo!" (Tereza, 22 anos).

Vencer o que consideram ser tentativas de silenciamento é um modo de autoafirmação em outra chave para recuperar uma imagem de confiança. Nas falas e na observação de campo, essa imagem de si parecia estar associada ao uso político do corpo, principalmente do cabelo, como instrumentos de afirmação de uma identidade de mulher preta, como elas chamam. O corpo é mobilizado como suporte para afirmações identitárias. Em uma ocasião em campo, uma professora elogiava o cabelo de Maria Firmina, que é cacheado, longo, usado com efeito molhado, com o volume sempre controlado. Em 2019, Dandara conta que cortou o cabelo para deixá-lo crescer com a textura natural, usando o Black Power. Os antigos elogios, que ouvia quando estava com o cabelo trançado, transformaram-se em comentários racistas, a sugerir que o fenótipo, mais propriamente o cabelo, apresentam-se como arena de disputas simbólicas. Tereza conta que, na mesma semana em que conversamos, ela foi alvo de racismo quando a proprietária da escola na qual trabalhava sugeriu que ela usasse lenços (turbantes) para esconder o seu cabelo crespo. A mobilização de elementos da estética corporal como exercício de resistência a faz ativar memórias da infância, pelas discussões que o cabelo provocava na família. 
Eu ouvia da minha mãe que meu cabelo tinha que estar preso, porque ele era feio, porque as outras pessoas não iam gostar de ver um cabelo assim. Que eu precisava sentar na frente porque eu não enxergava e, se eu usasse meu cabelo natural, eu ia atrapalhar o aprendizado das outras crianças. Então eu sempre cresci com essa preocupação de que: "poxa, eu vou atrapalhar, o meu cabelo vai atrapalhar". "Eu sou assim, mas eu não posso ser". Atrapalhava, por exemplo, a visão das outras crianças, porque as outras crianças não conseguiam enxergar o quadro, mas eu falava: "eu também não consigo enxergar, e aí". Só que eu tenho um problema de visão, é outra coisa. Tiveram que chamar a minha mãe pra reclamar, falar: "olha, dá um jeito porque não dá”. E é uma forma de fazer com que você não reconheça a sua própria identidade. Quando eu descobri como era o meu cabelo solto eu gostava muito dele, mas de tanto ouvir que ele era feio e que ele atrapalhava, que pra ser bonita eu teria que ter o cabelo liso, com dez anos eu alisei o meu cabelo e ele quebrou inteiro, é um cabelo muito sensível. Eu tive que cortar o meu cabelo extremamente curto, aí já entrou outra questão: "menina macho" (Tereza, 22 anos).

Seja enquanto aluna, enquanto professora, enquanto funcionária de uma escola, o racismo expresso nas manifestações contra o seu cabelo interpela a vida de Tereza em diferentes momentos de sua trajetória. Dandara conta também um caso de racismo que sofreu após cortar seu cabelo e assumir a textura natural. Para Gomes (2007), o cabelo e o corpo são símbolos da identidade negra, no processo que chama de rejeição/ aceitação/ ressignificação do cabelo crespo, que designa uma formulação identitária, para além de ser um mero penteado, enquanto tecnologia de moda. $\mathrm{O}$ penteado é forma de expressão da identidade.

Diante das situações de racismo e das tentativas de afirmação, as interlocutoras entrevistadas diziam: "Ser mulher negra é... ser resistência”. As jovens apresentaram essa resistência tanto como um processo de tornar-se negra e passar a vivenciar uma luta contra o racismo e o sexismo no seu cotidiano, quanto como uma militância política que perpassa a articulação com movimentos sociais. A resistência descenderia, segundo essas falas, de um processo de construção da autoestima enquanto mulheres negras.

E o que é esse processo?

De aceitação, de defender o que eu sou, de ouvir e muitas vezes buscar desconstruir aquilo que tá nos outros, porque é uma rotina diária, e de também entender. [...] são anos de estudo. Então é muito auto, o conhecimento ele é autopercepção daquilo que você vive. Toda maturidade pela experiência de vida que eu tenho - a maturidade vem através do sofrimento, se você não sofrer você não vai aprender. (Dandara, 18 anos). 
Questionada sobre o que é militância, Tereza responde que se trata de um dos componentes de sua identidade, uma forma de resistência. Apesar de ser filiada a um partido de esquerda, comunista, para Tereza, a militância acontece muito mais na forma de enfrentamento diário do que via partido, ou ação política coordenada. "Independente se eu tivesse a consciência política que eu tenho, eu continuo sendo uma mulher preta, sapatão, umbandista, e a sociedade não vai me deixar esquecer isso...”, diz ela.

Militar enquanto verbo, para as interlocutoras com quem houve diálogo, significa esse reconhecimento enquanto mulheres negras e essa postura de resistência frente ao racismo, sexismo, hipersexualização, preterimento, sentimento de incapacidade e silenciamento pelos quais passam. Resistência é enfrentar dia a dia os comentários racistas, a desconfiança contínua, e seguir se fortalecendo através da busca de pares.

As interlocutoras entrevistadas indicaram que sua construção identitária e sua resistência passam pela formação e profissão, como futuras professoras da educação infantil. Como observado, as mulheres que se identificam como pretas na pesquisa usam cabelos, roupas e acessórios como formas de reivindicar e exaltar um ideal de negritude. Elas usam tal mecanismo mesmo em sua atuação profissional, como estratégia para criar outra imagem para as crianças, agora numa acepção positiva.

Eu acho que é uma questão muito forte frente às crianças. Eu tenho uma só criança que tem o cabelo crespo onde eu trabalho, uma criança. Ela olha pra mim e quando eu coloquei trança ela falou: "porque seu cabelo não tá igual o meu?" A única referência que ela tem sou eu. Eu tento ser pra ela aquilo que eu não tive, entendeu? Porque eu lembro que pras minhas professoras brancas, na escola eu era sempre a criança que atrapalhava (Tereza, 22 anos).

Acreditar que você pode representar esses que não "existiram" é muito forte. É forte pra mim porque eu sou uma professora que está lá na frente falando com meu cabelo Black Power pra eles, e eles me conhecerem como a portadora do conhecimento que está ali na frente, eles acreditando em mim, é muito forte, assim, eles até olham pra mim e falam: "nossa professora, como que você fez esse cabelo, que eu também quero! É muito diferente seu penteado, é muito bonito!" (Dandara, 18 anos). 
A carência de referências que lhes servissem de exemplos na memória da infância surge assim como dificuldade de aceitação de um corpo que parece ser a todo momento rejeitado pelos demais e, consequentemente, por si mesmas. Pergunto se a escola influenciava essa percepção sobre si. Ela responde:

Você se sente desmotivado, sabe? Por mais que às vezes não aconteça um
caso, assim, um racismo bem explícito, mas você olha em volta, os professores,
a coordenação, quem está lá em cima, não tem nenhuma pessoa igual você,
nenhuma. Nossa, várias vezes de eu parar e me perguntar: "nossa, mas o que
eu estou fazendo, pra que? Eu não vou chegar lá onde eles estão". Eu acho que
todo o ambiente acaba influenciando dessa forma (Tereza, 22 anos).

Indagadas sobre o que significa serem professoras, a resposta de Tereza sugere insegurança acerca das situações de racismo que já enfrentou e que pode vir a enfrentar ao longo de sua profissão. Várias vezes ao longo de seu relato ela fala da vontade de revidar e se colocar expressamente contra o racismo, porém, entra em conflito com a necessidade objetiva de trabalhar. Para Dandara, a possibilidade de representar e defender as crianças negras se sobrepõe às possíveis situações de racismo a serem enfrentadas.

As resistências dessas estudantes-educadoras, em resumo, passam pela articulação com as memórias da infância, com o cotidiano da vida e do trabalho, para dizer o quadro social mais amplo em que estão inseridas. Estes são os elementos mobilizados na reivindicação de uma identidade negra. Como vimos, corpo e cabelo se transformam em munição para afirmação da negritude, como ação de resistência.

\section{Considerações finais}

O trabalho aqui apresentado buscou compreender processos de formação identitária de mulheres negras, elegendo a trajetória escolar como forma de acessar as socializações que se dão no espaço da escola. Entende-se que a construção das identidades é um processo relacional, que reclama alteridades, na demarcação do "eu" e do "outro". Ela assume igualmente representações coletivas, que dizem respeito a grupos, que disputam a legitimidade das suas formas de se representar. 
Na pesquisa com a escola de formação de docentes, enquanto houve convívio com essas estudantes negras matriculadas no curso, foi possível colher alguns indícios sobre a forma como a instituição se coloca frente a tais processos de construção de identidades negra. A negação e a aceitação da diversidade dos alunos, sobretudo no que toca a questão racial, mostra-se muito ambígua. A julgar pelas associações de problemas com alunas "militantes", ou sobre quando o tema raça emerge durante as aulas, ou ainda o modo como os corpos são representados e percebidos pelos agentes responsáveis pela sala (professores), pela manutenção da escola (funcionários administrativos) e pela administração (coordenadores), que, por meio de práticas, legitimam e deslegitimam pleitos e comportamento das alunas e alunos, que desembocam numa representação da(o) aluna(o) ideal. A tentativa foi de mostrar como esse ideal está distante da inclusão de perfis diferentes, que comporte a diversidade racial da escola.

Em outro sentido, a análise das relações sociais entre as alunas, ou entre alunas e professores, evidenciam como a identidade negra é também essencializada. Nesta acepção, apresentamos seu uso politizado, porém este fazendo frente às mulheres negras de pele clara que têm sua identidade questionada. Professores e colegas de sala se mostraram ambíguas quando o tema era definir quem era branco e quem era negro em sala, rejeitando, por vezes, as demandas do grupo que se afirmava na chave da negritude. Ao que as evidências sugerem, a instituição parece ter dificuldade em lidar com essas identidades cada vez mais articuladas enquanto elemento de mobilização política.

Em contrapartida, a educação surge como um recurso mobilizado pelas mulheres negras dessa escola como componente de suas identidades e militâncias. É por isso que, para elas, ser professora negra, vai além de um projeto de carreira profissional, é também um projeto de vida, que serve como militância. Desse modo, atuar como docentes significa ao mesmo tempo, ofertar um exemplo para crianças negras e lutar contra o racismo que se manifesta.

Como vimos, as trajetórias das alunas falam de opressões, silenciamentos e outras violências, mas falam, sobretudo, de resistências. Afirmar essas identidades que frequentemente são contestadas em diversos contextos, inclusive por meio do corpo e 
do que chamam de militância, são formas através das quais elas elaboram sua resistência.

\section{Referências}

ARROYO, Miguel. Os Movimentos Sociais e a construção de outros currículos. Educar em Revista, [S.1.], n. 55, p.47-68, mar. 2015.

BATISTA, Matheus do N. et al. O autoconceito cognitivo de estudantes pretos (as) e pardos (as). Psicologia Argumento, [s.1.], v. 37, n. 97, p. 299-311, 11 fev. 2020.

CARNEIRO, Sueli. Mulheres em movimento. Estudos avançados, v. 17, p. 117-133, 2003 .

CARVALHO, José J. de; SEGATO, Rita L. Uma proposta de cotas para estudantes negros na Universidade de Brasília. Série Antropologia 314, Brasília, p.1-52, 2004.

CARVALHO, Marília P. de. O fracasso escolar de meninos e meninas: articulações entre gênero e cor/raça. Cadernos Pagu, Campinas, n. 22, p. 247-290, Jun. 2004.

CASTELAR, Marilda et al. Brinquedos e brincar na vida de mulheres educadoras negras. Psicologia Escolar e Educacional, [S.1.], v. 19, n. 3, p.595-602, dez. 2015.

CAVALLEIRO, Eliane. Relações raciais no cotidiano escolar: implicações para a subjetividade e a afetividade. In: BRANDÃO, Ana P. (Org.). Saberes e fazeres: modos de ver. Rio de Janeiro: Fundação Roberto Marinho, 2006. Cap. 7. p. 82-96.

COLLINS, Patrícia H. Em direção a uma nova visão: Raça, classe e gênero como categorias de análise e conexão. In: MORENO, Renata (Org.). Reflexões e práticas de transformação feminista. São Paulo: Sof, 2015. Cap. 1. p. 13-42. (Coleção Cadernos Sempreviva. Série Economia e Feminismo, 4).

CRENSHAW, Kimberlé. A intersecionalidade na discriminação de raça e gênero. VV. AA. Cruzamento: raça e gênero. Brasília: Unifem, p. 7-16, 2004.

CRENSHAW, Kimberlé. Mapping the Margins: Intersectionality, Identity Politics and Mapping the Margins. Kvinder, Køn \& Forskning, [S.l.], p. 2-3, 2006.

DA MATTA, Roberto. O ofício do etnólogo ou como ter anthropological blues. Boletim do Museu Nacional, Rio de Janeiro, n. 27, p.1-12, maio 1978.

DUSCHATZKY, Silvia; SKLIAR, Carlos. Os Nomes dos Outros. Reflexões sobre os Usos Escolares da Diversidade. Educação \& Realidade, Porto Alegre, v. 25, n. 2, 2000. 
GOMES, Nilma L. Educação, identidade negra e formação de professores/as: um olhar sobre o corpo negro e o cabelo crespo. Educação e Pesquisa, São Paulo, v. 29, n. 1, p. 167-182, Jun. 2003.

GOMES, Nilma L. Educação, raça e gênero: relações imersas na alteridade. Cadernos Pagu, Campinas, n. 6/7, p. 67-82, Jan. 1996.

GOMES, Nilma L. O processo de rejeição/aceitação/ressignificação do corpo e do cabelo. In: GOMES, Nilma L. Sem perder a raiz: corpo e cabelo como símbolos da identidade negra. 2. ed. Belo Horizonte: Autêntica, 2008. Cap. 2. p. 117-166.

GOMES, Nilma L. Indagações sobre currículo: diversidade e currículo. Brasília: Ministério da Educação, Secretaria de Educação Básica, 2007. 48 p.

GONÇALVES, Luiz A. O. O silêncio: um ritual pedagógico a favor da discriminação racial. 1985. 342 f. Dissertação (Mestrado) - Curso de Mestrado em Educação, Universidade Federal de Minas Gerais, Belo Horizonte, 1985.

GONCALVES, Luiz; SILVA, Petronilha. Movimento negro e educação. Rev. Bras. Educ., Rio de Janeiro, n. 15, p.134-158, Dez. 2000.

GONZALEZ, Lélia. Racismo e sexismo na cultura brasileira. Revista Ciências Sociais Hoje, [S.l.], v. 2, n. 1, p. 223-244, 1984.

GUIMARÃES, Antonio S. A. Racismo e anti-racismo no Brasil. Novos Estudos: CEBRAP, S.I., n. 43, p. 26-44, nov. 1995.

HALL, Stuart. A identidade cultural na pós-modernidade. 11. ed. Rio de Janeiro: DP\&A Editora, 2006. 101 p. Tradução de: Tomaz Tadeu da Silva e Guacira Lopes Louro.

HASENBALG, Carlos; SILVA, Nelson do V. Raça e oportunidades educacionais no Brasil. Cadernos de pesquisa, n. 73, p. 5-12, 1990.

INSTITUTO Brasileiro de Geografia e Estatística. Censo Demográfico 2o1o: Características da população e dos domicílios. Rio de Janeiro: IBGE, 2011. 270 p.

LOURO, Guacira L. Gênero, sexualidade e educação: uma perspectiva pósestruturalista. 2 ed. Petrópolis, RJ: Vozes, 1997, 184 p.

MAGGIE, Yvonne; FRY, Peter. O debate que não houve: a reserva de vagas para negros nas universidades brasileiras. Enfoques: Revista Eletrônica, Rio de Janeiro, v. o1, n. 1, p. 93-117, 2002. 
MUNANGA, Kabengele. Negritude e identidade negra ou afrodescendente: um racismo ao avesso? Revista da Associação Brasileira de Pesquisadores/as Negros/as (ABPN), Uberlândia, v. 4, n. 8, p. o6-14, 2012.

MUNANGA, Kabengele. Uma abordagem conceitual das noções de raça, racismo, identidade e etnia. In: 3o Seminário Nacional Relações Raciais e Educação PENESB, Rio de Janeiro, nov. 2003.

NOGUEIRA, Oracy. Preconceito racial de marca e preconceito racial de origem: sugestão de um quadro de referência para a interpretação do material sobre relações raciais no Brasil. Tempo social, São Paulo, v. 19, n. 1, p. 287-308, jun. 2007.

QUIJANO, Aníbal. A colonialidade do saber: eurocentrismo e ciências sociais. In: Perspectivas latino-americanas. Buenos Aires: CLACSO, p. 117-142, 2005.

ROSEMBERG, Fúlvia. Relações raciais e rendimento escolar. Cadernos de Pesquisa, n. 63. p. 19-23, 1987.

SEGATO, Rita L. O Édipo brasileiro: a dupla negação de gênero e raça. Série Antropologia, Brasília, n. 400, 2006.

SEGATO, Rita L. Raça é signo. Série Antropologia 372, Brasília, p.1-16, 2005.

WALSH, Catherine. Interculturalidade crítica e pedagogia decolonial: in-surgir reexistir e re-viver. In: CANDAU, Vera M. Educação intercultural na América Latina: entre concepções, tensões e propostas. Rio de Janeiro: 7letras, 2009. 32 p.

WOODWARD, Kathryn. Identidade e diferença: uma introdução teórica e conceitual. In: SILVA, Tomaz T. da. Identidade e Diferença. A perspectiva dos Estudos Culturais. 15. ed. Petrópolis, RJ: Vozes, 2014. 